University of Nebraska - Lincoln

DigitalCommons@University of Nebraska - Lincoln

Faculty Papers and Publications in Animal

Science

Animal Science Department

June 1998

\title{
Genetic and Phenotypic Parameters for Carcass Traits of American Shorthorn Beef Cattle
}

\author{
F. Pariacote \\ University of Nebraska-Lincoln \\ R. E. Hunsley \\ American Shorthorn Association, 8288 Hascall St., Omaha, NE \\ L. Dale Van Vleck \\ University of Nebraska-Lincoln, dvan-vleck1@unl.edu
}

Follow this and additional works at: https://digitalcommons.unl.edu/animalscifacpub

Part of the Animal Sciences Commons

Pariacote, F.; Hunsley, R. E.; and Van Vleck, L. Dale, "Genetic and Phenotypic Parameters for Carcass Traits of American Shorthorn Beef Cattle" (1998). Faculty Papers and Publications in Animal Science. 275.

https://digitalcommons.unl.edu/animalscifacpub/275

This Article is brought to you for free and open access by the Animal Science Department at DigitalCommons@University of Nebraska - Lincoln. It has been accepted for inclusion in Faculty Papers and Publications in Animal Science by an authorized administrator of DigitalCommons@University of Nebraska - Lincoln. 


\title{
Genetic and Phenotypic Parameters for Carcass Traits of American Shorthorn Beef Cattle ${ }^{1}$
}

\author{
F. Pariacote*,2, L. D. Van Vleck ${ }^{\dagger, 3}$, and R. E. Hunsley \\ *Department of Animal Science, University of Nebraska, Lincoln 68583-0908; \\ tRoman L. Hruska U.S. Meat Animal Research Center, \\ USDA, ARS, Lincoln, NE 68583-0908; and \\ ¥American Shorthorn Association, 8288 Hascall St., Omaha, NE 68124
}

\begin{abstract}
Carcass measurements were taken on 1,292 steers and collected by the American Shorthorn Association. The sires were purebred or appendixregistered Shorthorn. Because all dams were not Shorthorn, genetic fractions of breeds of origin were determined for each dam. Measurements for hot carcass weight; dressing percentage; fat thickness; ribeye area; kidney, pelvic, and heart fat $(\mathrm{KPH})$; marbling; and yield grade were analyzed jointly with a multivariate REML algorithm to estimate heritabilities of and genetic and phenotypic correlations among the traits. The sire model chosen as best fit of the data included fixed effects of herd of origin (377 classes), slaughter group (118 classes), year of birth (1979-1995), and covariates for linear effects of genetic fractions of breeds (13) of dam and slaughter age, with sire $(\mathrm{n}=409)$ as a random effect. Estimates of heritability were $.60 \pm .19, .49 \pm .19, .46 \pm .19, .97 \pm$ $.21, .45 \pm .19, .88 \pm .21$, and $.54 \pm .19$ for previous order of traits, respectively. Most genetic correlations were not significantly different from zero. Genetic correlations of hot carcass weight were significant and positive with dressing percentage $(.65 \pm .19)$ and with
\end{abstract}

ribeye area (.70 \pm .14). Dressing percentage was significantly positively genetically correlated with ribeye area $(.79 \pm .16)$ and negatively genetically correlated with yield grade $(-.56 \pm .29)$. Yield grade was also significantly negatively genetically correlated with ribeye area $(-.85 \pm .10)$ and positively genetically correlated with fat thickness $(.67 \pm .15)$. Most phenotypic correlations were significant and positive. Only the phenotypic correlations of dressing percentage with marbling and with yield grade, and ribeye area with KPH and with marbling were not significantly different from zero. Significant negative corre lations were fat thickness with ribeye area $(-.16 \pm$ $.04)$ and ribeye area with yield grade $(-.61 \pm .03)$. Results seem to indicate that genetic antagonisms between quantity and quality traits were small to moderate. Thus, the opportunity seems to exist for breeding plans to improve carcass quality without having any adverse genetic effect on hot carcass weight, dressing percentage, or ribeye area. The high heritability observed for marbling indicates that a low genetic potential for marbling can be remedied by selection within breed.

Key Words: Beef Cattle, Genetic Parameters, Carcass Quality

@1998 American Society of Animal Science All rights reserved.

J. Anim. Sci. 1998. 76:2584-2588

\section{Introduction}

Beef cattle breeders have put emphasis on growth, and packers have put emphasis on lean meat content as well as marbling and quality grade. Major goals for beef cattle breeding seem to be to maximize muscle

\footnotetext{
${ }^{1}$ Published as paper no. 11842, J ournal Ser., Nebraska Agric. Res. Div., Univ. of Nebraska, Lincoln 68583-0908.

${ }^{2}$ Current address: UNEFM, Departamento de Producción Animal, Apartado 7482, Coro, Venezuela 4101.

${ }^{3}$ To whom correspondence should be addressed: A218 Animal Sciences; phone: 402/472-6010; fax: 402/472-6362.

Received October 17, 1997.

Accepted J une 30, 1998.
}

tissue and minimize fat; both are consistent with consumer demand. Meat quality has become economically important (Dikeman, 1994; Kemp, 1994). The amount of intramuscular fat is an important factor in determining meat quality, because of its influence on eating quality (Dikeman, 1990; Koch et al., 1993; J ones and Tatum, 1994; Wheeler et al., 1994). However, backfat is the primary factor that affects cutability (Herring et al., 1994). Thus, fat content is related to both carcass yield and carcass quality. Fat content will probably decrease when selecting for lean meat yield (Lundström, 1990; Wheeler et al., 1994). Breeding strategies that maximize profit need to balance genetic potential for carcass yield with adverse correlated changes in quality of the product. 
Relationships among these traits often are characteristics of a population, so estimates within a given population are needed for application to practical breeding programs for that population. The objective of this study was to estimate genetic parameters such as heritabilities and genetic correlations for carcass traits of Shorthorn beef cattle.

\section{Materials and Methods}

Carcass measurements of 1,292 steers collected by the American Shorthorn Association were used to estimate genetic and phenotypic parameters. Records were classified by herd of origin, slaughter group, and individual year of birth. A slaughter group was a contemporary group fed and slaughtered together. Steers in a group were brought together from various breeders to a feedlot facility and managed under feedlot conditions usually under state supervision. Slaughter time was determined by three criteria: 1 ) when the group had been on feed a minimum of $90 \mathrm{~d}$, and(or ) 2) the group average age was $18 \mathrm{mo}$, and(or) 3) a visual evaluation indicated $1.27 \mathrm{~cm}$ of fat over the ribs or possibility of achieving USDA low Choice or higher quality grade.

All sires were Purebred or Appendix-Registered Shorthorn. Because all dams were not Shorthorn, fractions of breeds that contributed to the genotypes of the dams were determined for each dam. Dams were Angus, Brangus, Chianina, Charolais, Gelbvieh, Holstein, Hereford, Maine Anjou, Pinzgauer, Santa Gertrudis, Shorthorn, Simmental, or crossbred. Records with missing traits, unknown level of a fixed effect, and from females were not included. Family relationships among slaughter animals existed primarily through sires. Relationships among dams were not considered. Few dams had more than one progeny. Only one random record of a set of full-sibs was allowed. To maximize the sources of genetic information without unnecessarily increasing the number of equations, sire-of-sire and dam-of-sire identification numbers were assigned to each sire from the complete pedigree file of the breed to obtain a smaller pedigree file.

Traits were live weight at slaughter, taken within $24 \mathrm{hr}$ before slaughter; hot carcass weight; dressing percentage; fat thickness at 12th rib; kidney, pelvic, and heart fat ( KPH) by visual appraisal as percentage of carcass; ribeye area, as the cross-sectional area of the Longissimus muscle at the 12th rib; marbling score; and yield grade. Scores for marbling were assigned from low traces (2.5) to abundant plus (10.8) into 24 discrete categories (BIF, 1996). Yield grade was calculated as $2.5+.9843$ (fat thickness, $\mathrm{cm}$ ) $+.2 \mathrm{KPH}+.0084$ (hot carcass weight, $\mathrm{kg}$ ) -.0496 (ribeye area, $\mathrm{cm}^{2}$ ) (e.g., Romans et al., 1994). A descriptive summary of traits and covariates is shown in Table 1.

All traits were analyzed jointly with a multivariate canonical transformation algorithm to obtain REML estimates of (co)variances for sire and residual effects (Meyer, 1985). The REMLPK programs (Meyer, 1986) were used to carry out the analyses with the following sire model for a single trait with the usual extension for multiple traits, all measured on each animal:

$$
\mathbf{y}=\mathbf{X B}+\mathbf{Z u}+\mathbf{e}
$$

where

$$
\begin{aligned}
\mathbf{y}= & \text { the vector of observations, } \\
\mathbf{B}= & \text { vector of unobservable fixed effects, } \\
\mathbf{u}= & \text { vector of random related sire effects, } \\
\mathbf{X}= & \text { matrix that relates the fixed effects to } \\
& \mathbf{y ,} \\
\mathbf{z}= & \text { matrix that relates the elements of } \mathrm{u} \text { to } \\
& \mathrm{y}, \text { and } \\
\mathbf{e}= & \text { vector of residual effects. }
\end{aligned}
$$

Preliminary analyses resulted in a final vector of fixed effects that included herd of origin (377 classes), slaughter group (118 classes), individual year of birth (1979-1995), and the linear effects of genetic fractions of 13 breeds contributing to the dam and slaughter age as covariates. Number of sires was 409. Preliminary single-trait analyses resulted in near-zero estimates of variance that were due to maternal dam effects, so dam effects were not included in the model.

\section{Results and Discussion}

Fixed Effects. Fixed effects explained more than $60 \%$ of the variation for all traits. Herd of origin and slaughter group were significant $(P<.05)$ for all traits. Individual year of birth was significant ( $\mathrm{P}<$ .05) for live weight at slaughter, hot carcass weight, dressing percentage, and ribeye area. The linear covariate for slaughter age was significant $(P<.05)$ only for hot carcass weight. The effects of breed fractions of breed of dam were in agreement with previous studies that showed differences among breeds for carcass traits (J ohnston et al., 1992; Taylor and J ohnson, 1992; Van Vleck et al., 1992; Gregory et al., 1994a,b; Marshall, 1994; Taylor et al., 1996). The largest significant $(P<.05)$ differences among regression coefficients of traits for fractions of breeds of dam, in this study, were for marbling. Because these effects were peripheral to the purpose of this study and had large standard errors, they are not reported in more detail. 
Table 1. Unadjusted means $(n=1,292)$ and descriptive statistics for traits and covariates

\begin{tabular}{lrrrrr}
\hline \hline Variable & Mean & SD & CV & Min. & Max. \\
\hline Slaughter age, d & 485.2 & 57.7 & 11.9 & 336.0 & 865.0 \\
Live weight, kg & 552.7 & 53.4 & 9.7 & 365.1 & 756.1 \\
Hot carcass weight, kg & 344.9 & 38.4 & 11.1 & 219.5 & 477.6 \\
Dressing percentage & 62.4 & 2.4 & 3.8 & 49.9 & 77.0 \\
Fat thickness, cm & 1.0 & .4 & 40.9 & .0 & 2.8 \\
Ribeye area, cm & 81.7 & 10.3 & 12.6 & 49.7 & 120.0 \\
Kidney-pelvic-heart, \% & 2.5 & .7 & 27.3 & .5 & 5.0 \\
Marbling score & 5.3 & .9 & 16.2 & 2.8 & 9.2 \\
Yield grade & 2.8 & .8 & 26.6 & .7 & 5.6 \\
\hline
\end{tabular}

Heritability. Estimates of heritability shown on the diagonals of Table 2 are in the upper range reported in the literature reviews by Marshall (1994) and Koots et al. (1994a). Contrary to averages reported in these reviews, hot carcass weight had lower heritability than marbling. The same pattern of heritability estimates for carcass traits as in this study has been reported within and across breeds by Gregory et al. (1995). The estimates for ribeye area and marbling seem excessively large. Standard errors for large heritability estimates are usually smaller than for small heritability estimates. Thus, if confounding inflates heritability estimates, the standard errors will be deflated.

Genetic Correlations. Many of the estimates of genetic correlations shown in Table 2 were not significantly different from zero. Hot carcass weight was significantly highly positively correlated genetically with dressing percentage (.65) and with ribeye area (.70), slightly negatively correlated genetically with marbling, and moderately genetically correlated with fat thickness, KPH, and yield grade. Dressing percentage was significantly correlated genetically with ribeye area $(.79)$ and negatively correlated genetically with yield grade (-.56). Ribeye area was significantly negatively genetically correlated with yield grade $(-.85)$. Marbling was slightly positively correlated genetically with dressing percentage and $\mathrm{KPH}$, moderately negatively correlated genetically with ribeye area, and moderately positively correlated genetically with fat thickness and yield grade. Fat thickness and $\mathrm{KPH}$ were negatively correlated genetically with all traits except with marbling and yield grade. Yield grade was significantly correlated genetically with fat thickness (.67). The genetic correlation between fat thickness and $\mathrm{KPH}$ was moderate and negative.

These estimates of genetic correlations are within the ranges reported in the literature (Veseth et al., 1993; Wilson et al., 1993; Koots et al., 1994b; Marshall, 1994; Gregory et al., 1995), except for the correlation between fat thickness and hot carcass weight. The moderate and negative genetic correlation found between these two traits is contrary to that in the cited literature. However, the wide range of reported estimates seems to indicate that the genetic relationships among carcass traits may vary with the breed or population, or simply may be due to sampling variance because most studies, including this study, have relatively few observations.

For this population and for the range of slaughter age of the data, hot carcass weight, dressing percentage, and ribeye area seem to be highly interrelated genetically and to a lesser extent phenotypically. These traits are generally lowly to moderately negatively correlated with fat measurement traits (fat thickness, KPH, and marbling). The genetic correlations are moderately negative and near zero with marbling. The genetic correlations with yield grade are moderately to strongly negative. Results from this study suggest that a genetic increase in hot carcass weight at a constant age end point will increase

Table 2. Estimates ${ }^{\mathrm{a}}$ of heritability and genetic and phenotypic correlations with standard errors (SE)

\begin{tabular}{|c|c|c|c|c|c|c|c|}
\hline 1 Hot carcass weight & $.60 \pm .19$ & $.41 \pm .03$ & $.19 \pm .04$ & $.47 \pm .03$ & $.11 \pm .04$ & $.09 \pm .04$ & $.20 \pm .04$ \\
\hline 2 Dressing percentage & $.65 \pm .19$ & $.49 \pm .19$ & $.19 \pm .04$ & $.31 \pm .04$ & $.11 \pm .04$ & $.04 \pm .04$ & $.07 \pm .04$ \\
\hline 4 Ribeye area & $.70 \pm .14$ & $.79 \pm .16$ & $-.31 \pm .23$ & $.97 \pm .21$ & $-.05 \pm .04$ & $-.08 \pm .05$ & $-.61 \pm .03$ \\
\hline 5 Kidney-pelvic-heart & $-.30 \pm .29$ & $-.10 \pm .31$ & $-.21 \pm .33$ & $-.31 \pm .24$ & $.45 \pm .19$ & $.10 \pm .04$ & $.37 \pm .04$ \\
\hline 6 Marbling & $-.10 \pm .23$ & $.08 \pm .24$ & $.26 \pm .24$ & $-.17 \pm .19$ & $.10 \pm .25$ & $.88 \pm .21$ & $.22 \pm .04$ \\
\hline
\end{tabular}

${ }^{a}$ Genetic correlations are below, heritabilities on, and phenotypic correlations above diagonal. 
dressing percentage and ribeye area with slightly negative correlated response in marbling due to the small negative genetic correlations that seem to exist for ribeye area and hot carcass weight with marbling. Similarly, improvement in marbling would seem to have little adverse genetic effects on hot carcass weight at a given age. Further investigation seems necessary to determine the effects rate of maturity or mature size on the correlation between marbling and hot carcass weight.

Phenotypic Correlations. Estimates of phenotypic correlations are also shown in Table 2. Most phenotypic correlations were significant and positive, although not large. Only the phenotypic correlations of dressing percentage with marbling and with yield grade, and ribeye area with $\mathrm{KPH}$ and with marbling were not significantly different from zero. Significantly negatively correlated were fat thickness with ribeye area $(-.16)$ and ribeye area with yield grade (-.61). Hot carcass weight was lowly correlated with $\mathrm{KPH}$ and yield grade, moderately correlated with dressing percentage and yield grade, and highly correlated with dressing percentage and ribeye area. Dressing percentage was lowly correlated with $\mathrm{KPH}$ and moderately correlated with ribeye area. Fat thickness was moderately correlated with $\mathrm{KPH}$ and marbling and was highly correlated with yield grade. Marbling was lowly correlated with $\mathrm{KPH}$, and $\mathrm{KPH}$ was moderately correlated with yield grade. Marbling was moderately correlated with yield grade. The largest phenotypic correlations except for hot carcass weight and ribeye area are for the traits in the yield grade equation with yield grade. These correlations were based on a constant (adjusted) slaughter age.

Estimates of phenotypic correlations are in agreement with the literature reviews by Marshall (1994) and Koots et al. (1994a). Results indicate that heavier hot carcasses tend to have more fat thickness at the 12th rib and a greater fraction of $\mathrm{KPH}$ than lighter carcasses. Heavier hot carcasses tend also to have higher dressing percentage and greater area of the cross section of the Longissimus muscle at the 12th rib than lighter carcasses with little loss of marbling. Carcasses with greater ribeye area would be expected to have less fat thickness, smaller yield grade, and little loss of marbling.

\section{Implications}

Breeding strategies to increase genetic potential for hot carcass weight, which is the greatest determinant of carcass value at a constant age at slaughter, will increase the genetic potential for area of the cross section of the Longissimus muscle at the 12th rib and dressing percentage but may slightly reduce scores for marbling and tend to increase measurements of fat over the 12th rib and percentage of fat in the kidney- pelvic-heart area as a fraction of carcass weight. A slight genetic antagonism may exist between ribeye area and marbling. Opportunity seems to exist for breeding plans to improve marbling with little adverse genetic effect on carcass weight, ribeye area, or dressing percentage on a constant slaughter-age basis and with little increase in fraction of fat deposited in the kidney-pelvic-heart area or in fat thickness over the ribs. The high heritability observed for marbling suggests that low genetic potential for this measure of marbling can be remedied by selection within the breed.

\section{Literature Cited}

BIF. 1996. Guidelines for uniform beef improvement programs. Beef Improvement Federation, Oklahoma State Univ., Stillwater.

Dikeman, M. E. 1990. Genetic effects on the quality of meat from cattle. Proc. 4th World Congr. Genet. Appl. Livest. Prod. 15: 521-530.

Dikeman, M. E. 1994. Genetics of meat quality. Proc. 5th World Congr. Genet. Appl. Livest. Prod. 19:437-438.

Gregory, K. E., L. V. Cundiff, and R. M. Koch. 1995. Genetic and phenotypic (co)variances for growth and carcass traits of purebred and composite populations of beef cattle. J . Anim. Sci. 73:1920-1926.

Gregory, K. E., L. V. Cundiff, R. M. Koch, M. E. Dikeman, and M. Koohmaraie. 1994a. Breed effects and retained heterosis for growth, carcass, and meat traits in advanced generations of composite populations of beef cattle. J . Anim. Sci. 72:833-850.

Gregory, K. E., L. V. Cundiff, R. M. Koch, M. E. Dikeman, and M. Koohmaraie. 1994b. Breed effects, retained heterosis, and estimates of genetic and phenotypic parameters for carcass and meat traits of beef cattle. J. Anim. Sci. 72:1174-1183.

Herring, W. O., S. E. Williams, J. K. Bertrand, L. L. Benyshek, and D. C. Miller. 1994. Comparison of live and carcass equations predicting percentage of cutability, retail product weight, and trimmable fat in beef cattle. J. Anim. Sci. 72:1107-1118.

J ohnston, D. J .. J . M. Thompson, and K. Hammond. 1992. Additive and nonadditive differences in postweaning growth and carcass characteristics of Devon, Hereford, and reciprocal-cross steers. J. Anim. Sci. 70:2688-2694.

J ones, B. K., and J. D. Tatum. 1994. Predictors of beef tenderness among carcasses produced under commercial conditions. J. Anim. Sci. 72:1492-1501.

Kemp, R. A. 1994. Genetics of meat quality in cattle. Proc. 5th World Congr. Genet. Appl. Livest. Prod. 19:439-445.

Koch, R. M., J . D. Crouse, M. E. Dikeman, L. V. Cundiff, and K. E. Gregory. 1993. Effect of marbling on variation and change in beef tenderness in Bos taurus and Bos indicus crosses. USDA, ARS. Roman L. Hruska U. S. Meat Animal Research Center and UNL College of Agriculture. Beef Research, Prog. Rep. No. $4: 63-64$.

Koots, K. R., J. P. Gibson, C. Smith, and J. W. Wilton. 1994a. Analyses of published genetic parameter estimates for beef production traits. 1. Heritability. Anim. Breed. Abstr. 62 309-338.

Koots, K. R., J. P. Gibson, and J. W. Wilton. 1994b. Analyses of published genetic parameter estimates for beef production traits. 2. Phenotypic and genetic correlations. Anim. Breed. Abstr. 62:825-853.

Lundström, K. 1990. Genetics of meat quality. Proc. 4th World Congr. Genet. Appl. Livest. Prod. 15:507-510.

Marshall, D. M. 1994. Breed differences and genetic parameters for body composition traits in beef cattle. J. Anim. Sci. 72: 2745-2755 
Meyer, K. 1985. Maximum likelihood estimation of variance components for a multivariate mixed model with equal design matrices. Biometrics 41:153-165.

Meyer, K. 1986. Restricted maximum likelihood to estimate genetic parameters-in practice. Proc. 3rd World Congr. Genet. Appl. Livest. Prod. 12:454-459.

Romans, J. R., W. J . Costello, C. W. Carlson, M. L. Greaser, and K. W. J ones. 1994. The Meat We Eat. Interstate Publishers, Inc., Danville, IL.

Taylor, D. G., and E. R. J ohnson. 1992. Visual marbling score and chemical fat content of $\mathrm{M}$. longissimus in beef carcasses. Proc. Aust. Soc. Anim. Prod. 19:71-73.

Taylor, D. G., E. R. J ohnson, and L. Knoti. 1996. The accuracy of rump P8 fat thickness and twelfth rib fat thickness in predicting beef carcass fat content in three breed types. Proc. Aust. Soc. Anim. Prod. 21:193-195.
Van Vleck, L. D., A. F. Hakim, L. V. Cundiff, R. M. Koch, J. D. Crouse, and K. G. Boldman. 1992. Estimated breeding values for meat characteristics of crossbred cattle with an animal model. J. Anim. Sci. 70:363-371.

Veseth, D. A., W. L. Reynolds, J . J . Urick, T. C. Nelsen, R. E. Short, and D. D. Kress. 1993. Paternal half-sib heritabilities and genetic, environmental, and phenotypic correlation estimates from randomly selected Hereford cattle. J. Anim. Sci. 71: 1730-1736.

Wheeler, T. L., L. V. Cundiff, and R. M. Koch. 1994. Effect of marbling degree on beef palatability in Bos taurus and Bos indicus cattle. J. Anim. Sci. 72:3145-3151.

Wilson, D. E., R. L. Willham, S. L. Northcutt, and G. H. Rouse. 1993. Genetic parameters for carcass traits estimated from Angus field records. J. Anim. Sci. 71:2365-2370. 